\title{
IMPLEMENTASI CMS WORDPRESS PADA E-COMMERCE UNTUK PELAYANAN KATERING CV. ALAM JAYA
}

\author{
Idam Risnaputra ${ }^{1)}$, Gandung Triyono ${ }^{2)}$ \\ ${ }^{1}$ Sistem Informasi, Fakultas Teknologi Informasi, Universitas Budi Luhur \\ ${ }^{1,2} \mathrm{Jl}$. Raya Ciledug, Petukangan Utara, Kebayoran Lama, Jakarta Selatan 12260 \\ E-mail : idaemrisna@gmail.com ${ }^{1)}$, gandung.triyono@budiluhur.ac.id ${ }^{2}{ }^{2}$
}

\begin{abstract}
Abstrak
Perkembangan teknologi saat ini membawa dampak besar dalam dunia bisnis, salah satunya dengan website ecommerce kebutuhan bisnis saat ini sangat terpenuhi dari segi kecepatan, keamanan dan ketepatan serta meminimalisir kesalahan. Dalam CV. Alam Jaya terdapat permasalahan yang dihadapi yaitu terbatasnya media promosi dan jangkauan pemasaran. Hal ini disebabkan karena usaha yang digeluti sebelumnya adalah kontruksi serta media promosi saat ini dilakukan dengan cara mouth to mouth atau hanya batas kepercayaan. Metode penelitian ini menggunakan business model canvas yang dikembangkan menggunakan sistem Search Engine Optimisazion (SEO) dan Content Management System (CMS). Tujuan dari penelitian ini adalah agar web yang dikembangkan dapat dengan mudah menempati ranking teratas pada halaman pencari web (search engine) dan selalu terupdate isi dan rankingnya. Hasil dari penelitian ini adalah dengan adanya website ecommerce, perusahaan bisa mengembangkan informasi tentang jenis usaha yang sedang dikerjakan sekarang dan perusahaan sudah bisa mempromosikan produknya secara global serta ada nya form review / ulasan untuk menambah kepercayaan pelangaan yang lainnya.
\end{abstract}

Kata kunci: Catering, E-Commerce, Website, SEO, Business Model Canvas

\section{PENDAHULUAN}

Internet berkembang seiring dengan perkembangan teknologi informasi yang dapat mengubah pandangan dalam dunia bisnis. Saat ini beberapa perusahaan di Indonesia mulai memanfaatkan internet untuk membantu proses bisnis mereka, hal ini dapat dibuktikan dengan meningkatnya transaksi jual-beli secara online ( $e$ commerce). Untuk bisnis kuliner, ketersediaan $e$ commerce dapat dimanfaatkan untuk tujuan tersebut, termasuk bisnis catering. Permasalahan yang dihadapi dengan pemesanan catering melalui telepon atau datang langsung adalah kurangnya informasi mengenai harga dan menu catering, proses pemesanan yang menggunakan banyak waktu, serta pembuatan laporan yang masih manual [1]. CV. Alam Jaya adalah perusahaan catering yang sudah berjalan 6 tahun. Perusahaan ini berdiri pada tahun 1994, awalnya usaha yang dijalankannya yaitu bidang kontruksi. namun pada tahun 2013 tidak memperpanjang lagi surat izin usaha kontruksinya dan merambah usaha barunya yaitu dibidang catering. Sistem pemesanan catering yang diterapkan sampai sekarang ini hanya melalui tender dan konvesional (media telepon). Media promosi yang dipakai saat ini hanya dari mulut ke mulut dan hanya batas kepercayaan. Perusahaan juga masih sulit mengembangkan informasi tentang jenis usaha cateringnya karna awalnya perusahaan ini bergerak dibidang kontruksi.

Berdasarkan uraian masalah diatas, maka penelitian ini membuat sistem web e-commerce pada
CV. Alam Jaya guna membantu pemilik dalam mempromosikan usaha cateringnya, pengolahan data dan transaksi. Kelebihan penilitian ini dibandingkan dengan penilitian sebelumnya Taufani, Riyadi dan Dewantara antara lain, yaitu tidak hanya membuat desain sistem informasi pemasaran berbasis web sajasebagai media promosi, tetapi juga bisa melakukan pemesanan dan pembayaran secara online bagi pelanggan.

\section{METODE PENELITIAN}

2.1. E-Commerce

Pengertian dari e-commerce yaitu menggunakan internet dan komputer dengan browser web untuk menawarkan, membeli, mengenalkan dan menjual produk. Manfaat dari penerapan e-commerce pada sebuah perusahaan yaitu perusahaan dapat memiliki sebuah pasar internasional. Bisnis dapat dijalankan tanpa harus terbentur pada batas negara dengan adanya teknologi digital. Biaya operasional dapat ditekan sedikit mungkin. Mempercepat waktu pemrosesan dan mengurangi resiko human error [2].

\subsection{Business Model Canvas}

Menurut Osterwalder \& Pigneur Sebuah model bisnis merupakan menggambarkan pemikiran tentang bagaimana sebuah organisasi menciptakan, memberikan dan menangkap nilai-nilai dari suatu bisnis. Konsep dari sebuah model bisnis harus sederhana, relevan, dan secara intuisi mudah 
dipahami dengan tidak bermaksud menyederhanakan fungsi perusahaan yang sangat kompleks [3].

\subsection{Content Management System}

Content Management System (CMS) merupakan sebuah sistem yang memberikan kemudahan kepada para penggunanya dalam mengelola dan mengadakan perubahan isi sebuah website dinamis tanpa sebelumnya dibekali pengetahuan tentang hal-hal yang bersifat teknis. Dengan demikian, setiap orang, editor, maupun penulis, setiap saat dapat menggunakannya secara leluasa untuk membuat, menghapus atau bahkan memperbarui isi website tanpa campur tangan langsung dari pihak webmaster [4].

\subsection{Penelitian Terkait}

Penelitian dari [5] yang membahas tentang perancangan bisnis dengan menggunakan model business model canvas pada gerai ivonie cookies. Penjualan yang dilakukan masih melayani pesanan saat masih musiman saja serta menjual produknya hanya lewat penjualan langsung pada konsumen. Dari hasil penelitian di dapat rancangan gambaran mengenai 9 blok Business model canvas dimana gerai Ivonie Cookies nantinya lebih berfokus pada acara - acara khusus, juga rancangan mengenai cara pemasaran apa yang baiknya dilakukan, dan pada perhitungan Finance Analysis, di dapat bahwa perancangan gerai Ivonie Cookies ini layak dilakukan, dan akan mengalami pengembalian investasi awal pada 2 tahun, 10 bulan, 6 hari setelah gerai Ivonie Cookies di dirikan.

Penelitian yang dilakukan oleh [6] yang membahas tentang penjualan online e-commerce menggunakan CMS Wordpress pada toko Soraya shop. Penjualan yang dilakukan pada toko Soraya shop masih dilakukan secara manual serta transaksi yang dilakukan secara manual. Dari uraian masalah tersebut maka diperlukan e-commerce agar bisa meningkatkan penjualan, luas pasaran, serta hubungan dengan pelanggan yang memungkinkan terciptanya kesetiaan pelanggan.

Penelitian dari [7] yang membahas tentang studi pada sistem informasi pemasaran untuk promosi CV. Intan Catering. Sistem Informasi yang digunakan mempunyai beberapa kelemahan diantaranya seperti brosur kurang efektif dan efisien dalam memberikan informasi kepada prospect customer, jangkauan pemasaran yang terbatas. Dengan dibuatnya desain sistem informasi pemasaran untuk promosi berbasis web diharapkan bisa mengatasi masalah kontinuitas pemasaran saat ini dalam memberikan informasi mengenai produk yang ditawarkan.
Dari ketiga peniltian jurnal terkait tersebut, peniliti menyimpulkan bahwa ada 3 perbedaan dari penilitian yang dilakukan dengan penilitian sebelumnya, yaitu :

a. Peniliti menggunakan SEO untuk meningkatkan pemasaran website melalui world wide web.

b. Peneliti menggunakan Midtrans sebagai alat pembayaran di website.

c. Peniliti menggunakan Sosial Media untuk menambah Brand Awareness agar lebih dikenal dan terkenal.

\section{HASIL DAN PEMBAHASAN}

\subsection{Use Case Diagram}

Use Case Diagram merupakan gambaran graphical dari beberapa atau semua use case, actor, dan interaksi diantara komponen-komponen tersebut yang memperkenalkan suatu sistem yang akan dibangun [8].

a. Use Case Diagram Account

Pada menjelaskan tentang use case diagram account yang terdiri dari akun saya, login, dan lupa password. dapat dilakukan oleh Pelanggan dan Admin.

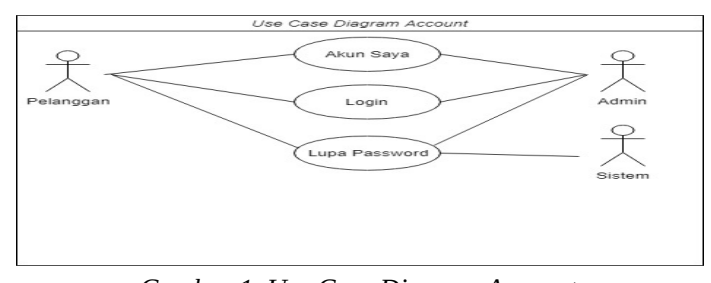

Gambar 1. Use Case Diagram Account

b. Use Case Diagram Master

Pada Gambar 2. menjelaskan tentang use case diagram master yang terdapat dua actor yang mempunyai perannya masing-masing, dari segi pelanggan yaitu melakukan registrasi dan dari segi Admin yaitu Entry Produk dan Entry Category.

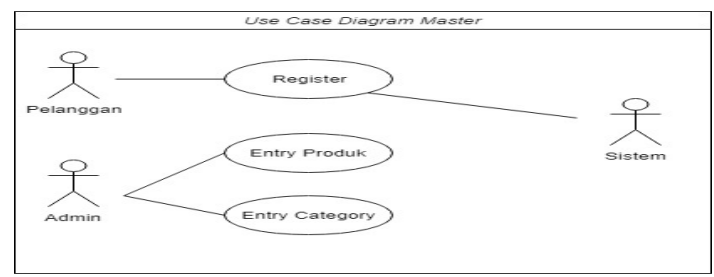

Gambar 2. Use Case Diagram Master

c. Use Case Diagram Transaksi

Pada Gambar 3. menjelaskan tentang use case diagram transaksi yang terdapat dua actor yang mempunyai perannya masing-masing, dari segi pelanggan yaitu melakukan Entry Pesanan dan Entry 
Pembayaran dan dari segi Admin yaitu Update Status Pesanan, Cetak Invoice dan Entry Surat Jalan.



Gambar 3. Use Case Diagram Transaksi

d. Use Case Diagram Laporan

Pada Gambar 4. menjelaskan tentang use case diagram laporan. Dapat dilakukan oleh admin untuk mencetak laporan.

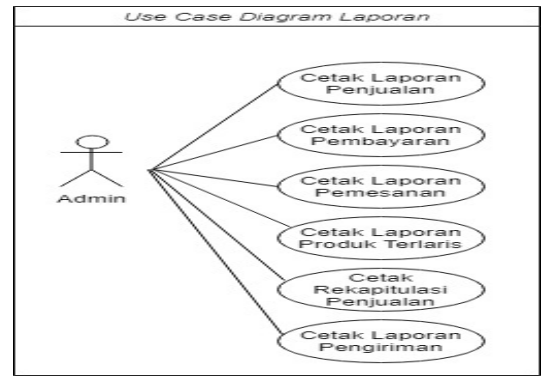

Gambar 4. Use Case Diagram Laporan

\subsection{Model Basis Data}

Class Diagram membantu dalam memvisualisasi struktur kelas-kelas dari suatu sistem dan hubungan antara kelas (inheritance, aggregation, association) dan penjelasan detail setiap kelas (function atau behavior atau method adalah apa yang dapat dilakukan oleh objek) [8]. Model Basis Data dapat dilihat pada Gambar 5.

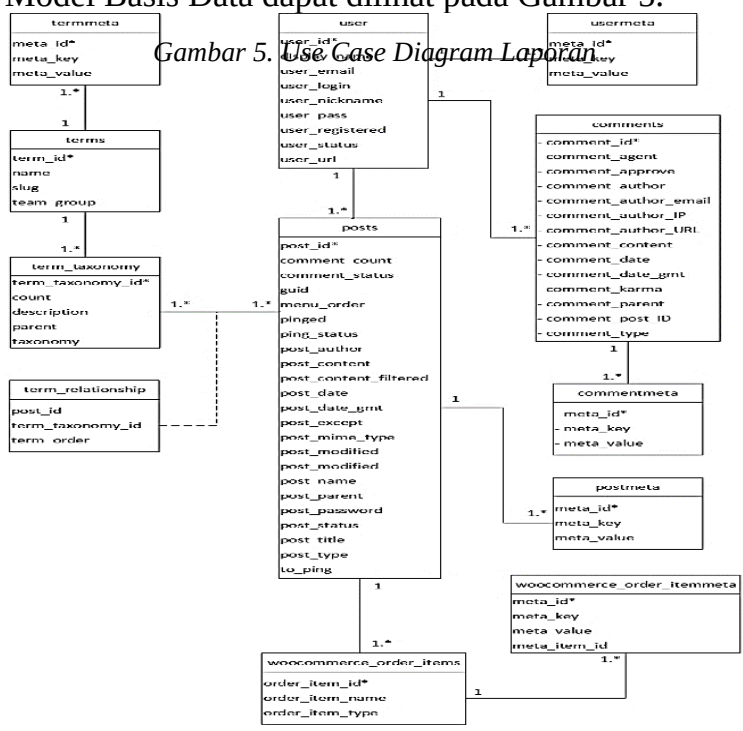

Gambar 5. Digambarkan dengan Class Diagram. Terdapat beberapa table yang terjadi pada class diagram Gambar 5, yaitu : Termmeta, Terms, Term_taxonomy, Term relationship, User, Posts, woocommerce_order_items, usermeta, comments, commentmeta, postmeta, woocommerce_order_item meta.

\subsection{Rancangan Layar}

Berikut adalah rancangan layar pada CV. Alam Jaya :

a. Rancangan Layar Register / Daftar

Berdasarkan Gambar 2, pada Use Case Diagram Register, maka dibuatkan rancangan layar seperti pada Gambar 7.

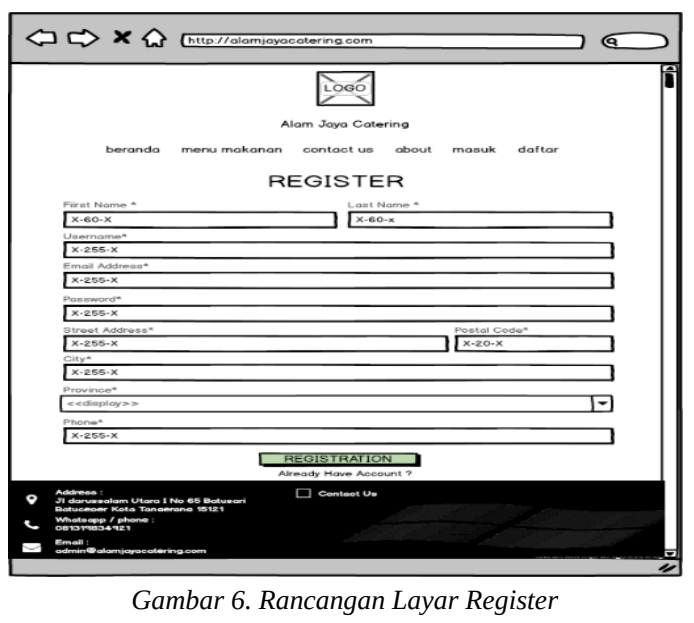

Gambar 7, menjelaskan ketika pelanggan ingin melakukan regsiter dan mengisi form yang tersedia.

b. Rancangan Layar Login / Masuk 
Berdasarkan Gambar 1. Pada Use Case Diagram Login, maka dibuatkan rancangan layar seperti pada Gambar 8.

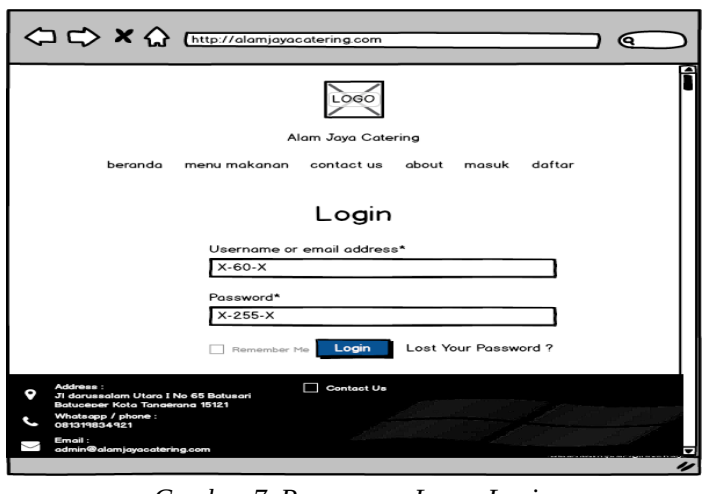

Gambar 7. Rancangan Layar Login

Gambar 8. menjelaskan ketika pelanggan ingin melakukan login dan mengisi username dan password yang telah terdaftar.

c. Rancangan Layar Lupa Password

Berdasarkan Gambar 3. Pada Use Case Diagram Lupa Password, Maka dibuatkan rancangan layar seperti pada Gambar 9.

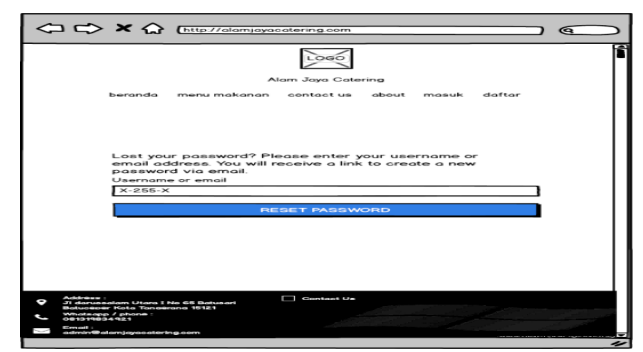

Gambar 8. Rancangan Layar Lupa Password

Gambar 9 menjelaskan ketika pelanggan lupa password dan mengisi username atau email yang telah terdaftar untuk mengganti password baru.

d. Rancangan Layar Menu Makanan

Berdasarkan Gambar 3. Pada Use Case Diagram Entry Pesanan, maka dibuatkan rancangan layar seperti pada Gambar 10.

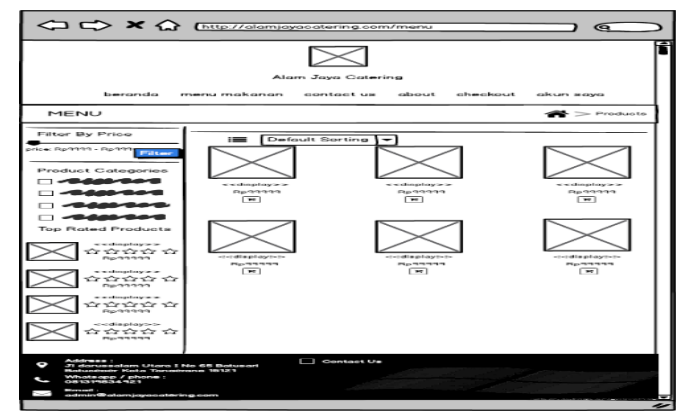

Gambar 9. Rancangan Layar Menu Makanan
Gambar 10. menjelaskan tampilan menu produk ketika pelanggan ingin melihat atau memesan produk CV. Alam Jaya.

\section{e. Rancangan Layar Contact Us}

Diperluka menu informasi kontak untuk pelanggan bisa menghubungi kontak perusahaan. Maka dibuatkan rancangan layar pada Gambar 11.

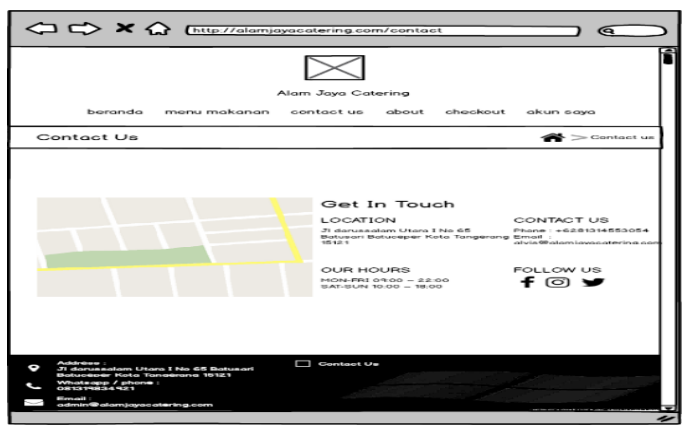

Gambar 10. Rancangan Layar Contact Us

Gambar 11, menjelaskan tampilan menu contact us untuk pelanggan mengetahui informasi kontak CV. Alam Jaya untuk dihubungi.

f. Rancangan Layar Akun Saya

Berdasarkan Gambar 3. Pada Use Case Diagram Entry Pesanan, maka dibuatkan rancangan layar seperti pada Gambar 12.

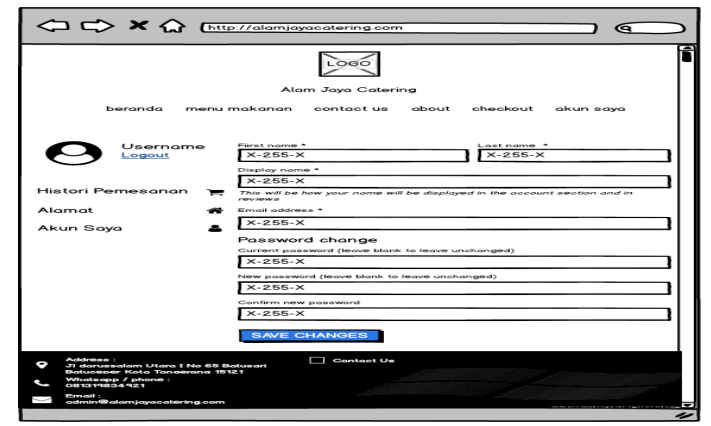

Gambar 11. Rancangan Layar Akun Saya

Gambar 12. menjelaskan tampilan menu akun saya ketika pelanggan yang sudah melakukan register ingin melakukan edit profile.

\section{g. Rancangan Layar Checkout}

Berdasarkan Gambar 3. Pada Use Case Diagram Entry Pesanan, maka dibuatkan rancangan layar seperti pada Gambar 13. 




Gambar 12. Rancangan Layar Checkout

Gambar 13. menjelaskan ketika pelanggan ingin melakukan pembayaran pada pesanan yang telah dipesan dan mengisi form yang tersedia.

\subsection{Strategi Search Engine Optimization \& Marketing}

Setelah website dibuat, selanjutnya perlu dilakukan pengoptimalan SEO. untuk mempermudah pengoptimalan SEO yaitu dengan menggunakan plugin SEO by Yoast Premium. Plugin ini akan memberikan saran serta langkah yang harus dilakukan untuk mengoptimalkan SEO.

a. Hasil Penggunaan Strategi SEO.

Pada Gambar 14. adalah hasil penggunaan strategi SEO pada menu paket 4 alam jaya catering dengan keyword (menu paket nasi kotak cumi saus padang murah) terdapat pada pages pertama dan urutan teratas.

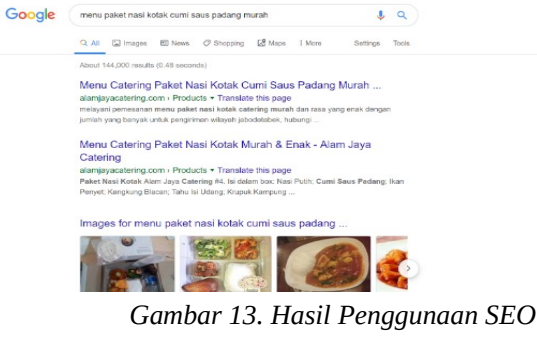

\section{b. Marketing}

Dalam segi marketing proses ini dilakukan untuk memasarkan produk dan informasi kepada pelanggan dengan berbagai macam cara, agar dapat menarik minat pelanggan. Berikut adalah Teknik marketing yang peneliti gunakan dalam penelitian ini :

\section{1) Instagram}

Gambar 15 adalah tampilan social media pada Instagram CV. Alam Jaya.

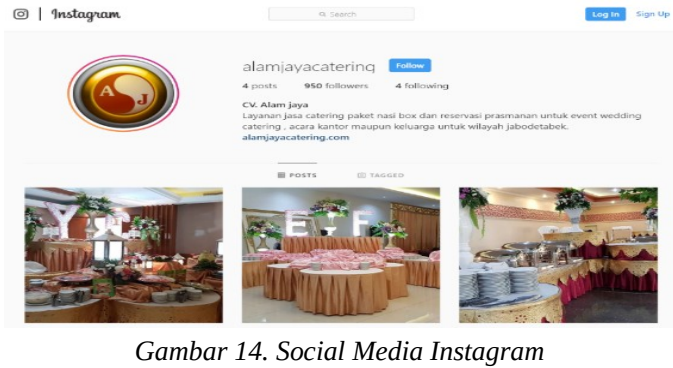

2) Facebook Page

Gambar 16. adalah tampilan social media pada Facebook Page CV. Alam Jaya.

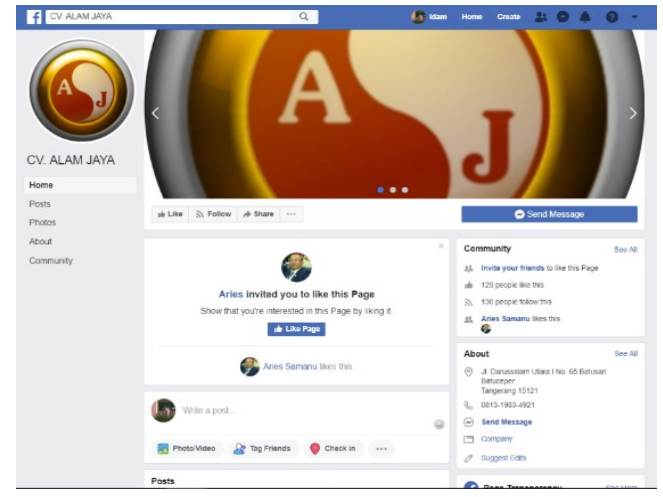

Gambar 15. Social Media Facebook Page

\section{KESIMPULAN}

Adapun kesimpulan yang didapatkan dari membuat website e-commerce pada CV. Alam Jaya, yaitu: dengan adanya website e-commerce, perusahaan sudah bisa mengembangkan informasi tentang jenis usaha yang sedang dikerjakan sekarang dan Perusahaan sudah bisa mempromosikan produknya secara global dan sudah ada form review / ulasan untuk menambah kepercayaan pelangaan yang lainnya.

\section{DAFTAR PUSTAKA}

[1] B. Humairah, "Mahir Membuat Website dengan Adobe Dreamweaver CS6 dan JQuery,” p. 35, 2015.

[2] S. Maulana, "Implementasi E-Commerce Sebagai Media Penjualan Online (Studi Kasus Pada Toko Pastbrik Kota Malang),” vol. 29, no. 1, 2015.

[3] L. Priska and D. Harjanti, "Strategi Pengembangan Bisnis Pada Depot Selaris Dengan Pendekatan Business Model Canvas,” vol. 3, no. 2, pp. 292-301, 2015.

[4] M. I. Alfarisyi and K. Amila, "Rancangan Sistem Informasi Layanan Alumni ITENAS Berbasis Web," vol. 02, no. 01, pp. 132-143, 2014.

[5] A. Salim, "Perancangan Bisnis Pada Gerai IVONIE COOKIES Kediri Dengan Menggunakan BUSINESS MODEL CANVAS,” vol. 4, no. 1, pp. 531-539, 2016. 
[6] D. Manulang, L. Abdillah, and Kurniawan, "Sistem Informasi Penjualan Online ( E-Commerce ) Menggunakan CMS Wordpress Pada Toko Soraya Shop,” pp. 7-12, 2017.

[7] M. K. Taufani, Riyadi, and R. Dewantara, "Analisis Dan Desain Sistem Informasi Pemasaran ( Studi pada Sistem Informasi Pemasaran untuk Promosi CV . Intan Catering ),” Taufani, Moh. Khafid, vol. 38, no. 2, pp. 1-10, 2016.

[8] D. Anggoro, M. D. Umar, and E. Vinanty, "Rancangan Sistem Informasi Koperasi Simpan Pinjam Guru Dan Pegawai,” vol. 2015, no. Sentika, pp. 213-222, 2015. 